\title{
Spanish as a Heritage Language in Europe
}

\author{
Francisca Ferre-Pérez \\ Consejería de Educación de Berlín, Spanish Embassy in Germany
}

\begin{abstract}
Heritage language education is becoming more and more important, as the relevance of the students' multilingual identity with a cultural background and an origin language different to the dominating one increases. Many researches in the USA focuses on the teaching of Spanish as a heritage language (Valdés 2000; Carreira, 2011 y 2018; Potowsky et al. 2009). In the European educational context, as the interest for bilingualism increases, it is argued that the students' multilingual identity and their heritage language should be considered at all educational levels (Gogolin, 2001). This communication gives an overview of the promotion of Iberian Spanish as a heritage language in Europe. The so called ALCE-program (Aulas de Lengua y Cultura Españolas) offers Spanish language and culture instruction to the immigrant Spaniards' children from the age of 7 to 17 in countries like Germany, Austria, Switzerland, Great Britain and France. This is one of the most important programs of the Spanish Education Ministry overseas. Interesting questions related to the teaching of Spanish heritage language like curricula, methodology, teachers' training, materials, and so on, as well as its organization within the reception country educational system will be introduced.
\end{abstract}

Keywords: ALCE; bilingual education; heritage language speakers; heritage language teaching; multilingual identity 